\title{
EVALUACIÓN DEL ESPESOR DE LA CRESTA INFRACIGOMÁTICA PARA LA COLOCACIÓN DE MINITORNILLOS MEDIANTE TOMOGRAFÍA COMPUTARIZADA DE HAZ CÓNICO
}

\author{
THICKNESS OF THE INFRAZYGOMATIC CREST, EVALUATED BY CONE BEAM \\ COMPUTED TOMOGRAPHY \\ Ana María Agudelo Botero ${ }^{1}$ \\ ortoamariabotero@gmail.com \\ ORCID: 0000-0002-0658-8517
}

\section{RESUMEN}

Introducción: Para colocar miniimplantes de anclaje ortodóncico es necesario evaluar el hueso en el sitio de implantación. El objetivo de este estudio fue determinar la existencia de hueso infracigomático midiendo la altura y el espesor a nivel de la raíz mesiovestibular del segundo molar superior, a 2, 4 y $6 \mathrm{~mm}$ de la cresta alveolar, utilizando la tomografía computarizada de haz cónico (TCHC). Método: Se revisaron 127 TCHC de sujetos entre 17 a 75 años. Se determinó la existencia de hueso basados en el criterio de altura y presencia de contacto entre raíz y cortical. Cuando la altura de la cresta infracigomática era > $10 \mathrm{~mm}$ se tomaban medidas de espesor a 2, 4, y $6 \mathrm{~mm}$ de la cresta alveolar, y se compararon por género. Resultados: De 127 TCHC se midió la altura de la cresta solo en $70 \mathrm{TCHC}$. El intervalo del $95 \%$ de confianza para esta medida fue de 8,64 a $9,76 \mathrm{~mm}$, pero solamente en $28(40 \%)$ era $>10 \mathrm{~mm}$. Las medidas de espesor se tomaron solamente en esos
28 casos, obteniendo un promedio de $9,2 \mathrm{~mm}, 8,3 \mathrm{~mm}$ y $6,6 \mathrm{~mm}$ cuando se midió a 2, 4 y $6 \mathrm{~mm}$, respectivamente. No se encontraron diferencias significativas entre géneros. Conclusiones: Tanto la apreciación cualitativa del hueso como las mediciones de altura y espesor de la cresta infracigomática indican que la región a nivel del segundo molar superior no es un sitio seguro para la colocación de minitornillos.

Palabras clave: cresta infracigomática, minitornillo, tomografía computarizada de haz cónico

\section{ABSTRACT}

Introduction: In order to place orthodontic temporary anchorage devices it is necessary to evaluate bone quality and size in the intended site. The objective of this study was to measure bone thickness and height at the level of the mesiobuccal root of the upper second molar, $2 \mathrm{~mm}$, $4 \mathrm{~mm}$ and $6 \mathrm{~mm}$ away from the alveolar

Citar como: Agudelo-Botero A. Evaluación del espesor de la cresta infracigomática para la colocación de minitornillos mediante tomografía computarizada de haz cónico. Rev Cient Odontol (Lima). 2019; 7 (1): $11-22$.

1 Universidad Autónoma de Manizales (Manizales, Colombia), Universidad Militar Nueva Granada (CieO) (Bogotá, Colombia). 
crest, using Cone Beam Computed Tomography (CBCT). Methods: The design of the present research is descriptive, retrospective. 127 CBCT images from 17-75 year old patients, were reviewed. The presence of bone was determined based on qualitative criteria of height and contact between root and cortical. When the height of the infrazygomatic crest was $>10 \mathrm{~mm}$, thickness measurements were taken at 2, 4, and $6 \mathrm{~mm}$ from the alveolar crest. Results: Only in 70 of the 127 CBCT images the height of the ridge was measured. The 95\% confidence interval for bone height was: 8.64 to $9.76 \mathrm{~mm}$, but only in $28(40 \%)$ it was $>10 \mathrm{~mm}$. Thickness measurements, in those 28 cases, average $9.2 \mathrm{~mm}, 8.3 \mathrm{~mm}$ and $6.6 \mathrm{~mm}$ was at 2, 4 and $6 \mathrm{~mm}$, respectively. No significant differences between genders was found $(p>0.05)$. Conclusions: Both the qualitative assessment of bone and the height and thickness measurements of the infrazygomatic crest indicate that this region at the level of upper second molar is not a safe site to place temporary anchoring devices.

Keywords: Cone-beam computed tomography. Infrazygomatic crest. Mini implants.

\section{INTRODUCCIÓN}

Las mecánicas de tratamiento ortodóncico han mejorado con el empleo de minitornillos $\left({ }^{1}\right)$. Una complicación grave durante la inserción de estos en la cresta infra cigomática es la lesión de la raíz mesiobucal del molar maxilar o la perforación del seno maxilar $\left({ }^{2}\right)$. Otras están relacionadas con la alteración de estructuras vitales como los nervios y el seno maxilar. Para que esta inserción se pueda realizar exitosamente, es indispensable determinar si existe una cantidad suficiente de hueso, con densidad ósea adecuada y medir la altura y el espesor de la cresta infracigomática en el área de interés. La estabilidad del minitornillo debe permitir los movimientos deseados y evitar los indeseados, lo cual depende de la cantidad y calidad del hueso disponible $\left({ }^{3}\right)$.

La tomografía computarizada de haz cónico (TCHC), permite obtener información tridimensional exacta acerca del hueso disponible para colocar los minitornillos, sin que la dosis de radiación sea excesiva $\left({ }^{2}\right)$. Una zona adecuada para obtener anclaje sin interferir en el movimiento del molar, principalmente para distalizarlo, es la cresta infracigomática $\left({ }^{3}\right)$, la cual ha sido medida tanto en altura como en espesor, pero pocos autores han considerado los cambios en el espesor siguiendo la trayectoria de inserción $\left({ }^{4}\right)$.

El desarrollo embrionario, la histogénesis y las características histológicas de la cresta infracigomática han sido ampliamente documentados $\left(^{5-7}\right)$. También se ha establecido que el hueso cortical tiene un módulo de elasticidad mayor que el hueso trabecular, que lo hace más fuerte y resistente a la deformación, lo que le permite soportar mayor carga en situaciones clínicas y obtener un mejor anclaje $\left(^{8,9}\right)$.

La cresta cigomática es una cresta de hueso que emana de la placa bucal del proceso cigomático maxilar, lateral a las raíces del primer molar maxilar. Es una estructura ósea densa que constituye un pilar de hueso cortical en el proceso cigomático del maxilar $\left({ }^{10}\right)$. Los minitornillos son usados durante los tratamientos de ortodoncia para obtener anclaje, ya sea fijando los dientes de reacción $u$ obviando por completo la necesidad de la unidad de reacción $\left({ }^{1,4}\right)$. Se usan para incrementar el componente horizontal de la fuerza aplicada para cierre de espacios, intrusión de posteriores y anteriores, distalización molar, retracción en masa, tracción de caninos impactados 
y corrección de sobremordida $\left({ }^{11,12}\right)$. El uso de estos dispositivos de anclaje ha permitido superar las limitaciones previas de los movimientos ortodóncicos $(1,3,10,13,14)$.

La elección del sitio de inserción del minitornillo depende de la anatomía del tejido blando, la distancia interradicular, la morfología del seno maxilar, la localización del nervio, la profundidad del hueso bucolingual y el espesor de corticales bucal y lingual $\left({ }^{15}\right)$. Los factores que afectan su efectividad se relacionan con la geometría del implante, superficie química, rugosidad $\left({ }^{4,16}\right)$, localización del nervio, profundidad del hueso vestíbulolingual, espesor de las corticales vestibular y lingual, calidad y cantidad de hueso de soporte, carga masticatoria, técnica y ángulo de colocación, proximidad radicular, tejido blando adyacente y edad $\left({ }^{17,18}\right)$.

Aunque es más seguro ubicar el minitornillo en medio del área interproximal, hay casos en los cuales puede ser una ventaja ubicarlos más hacia la mesial o la distal, de acuerdo con el movimiento dental que se necesite para evitar reposiciones posteriores durante el tratamiento $\left({ }^{19}\right)$. El espesor del hueso cortical a $2 \mathrm{~mm}$ hacia apical de la cresta alveolar a $0^{\circ}$ de angulación muestra un buen contacto, porque estos sitios cercanos a la cresta alveolar tienen el hueso cortical que ocupa el espacio entre los lados bucal y lingual $\left({ }^{20}\right)$.

Los ortodoncistas han encontrado que el proceso cigomático es una región adecuada para colocar minitornillos y han proporcionado datos sobre el volumen óseo disponible para tal aplicación ${ }^{21,22}$. Algunas investigaciones recomiendan el uso de CBCT solo en casos específicos, otros han defendido su uso rutinario para el diagnóstico y tratamiento en ortodoncia, ya que brinda información adicional al diagnóstico, es asequible y brinda un gran beneficio para el clínico $\left.{ }^{(23}\right)$. Otros proponen la CBCT únicamente cuando se tiene una justificación clínica individual, clara y específica ${ }^{23,24}$ ).

Costa et al., $\left({ }^{25}\right)$ al evaluar diez regiones anatómicas del maxilar y la mandíbula, incluyendo la cresta infracogomática, concluyeron que las regiones extra alveolares disponibles para la colocación de TAD tienen un rango de longitud de 4 a 12 $\mathrm{mm}$. Liou et al. ( $\left.{ }^{3}\right)$ midieron en tomografías computarizadas de adultos el espesor de la cresta infracigomática a nivel del primer molar, a diferentes ángulos y posiciones con relación al plano oclusal, encontrando que el espesor óseo de esta cresta sobre el primer molar maxilar fue de 5 a $9 \mathrm{~mm}$, medido a una angulación de $40^{\circ}$ a $75^{\circ}$ con relación al plano oclusal y a una altura de 13 a $17 \mathrm{~mm}$ sobre el plano oclusal.

Baumgaertel y Hans $\left({ }^{26,27}\right)$ evaluaron la profundidad de hueso de la cresta infracigomática disponible para la ubicación de minitornillos ortodóncicos, en 29 cráneos secos de adultos, mediante imágenes de CBCT. La mayor longitud la encontraron a nivel del primer molar en la raíz meso vestibular seguida por la raíz disto vestibular. Los autores concluyeron que cuando se insertan minitornillos de $6 \mathrm{~mm}$ o más de longitud hay riesgo de perforación del seno maxilar.

Chen et al. $\left({ }^{28}\right)$ evaluaron el espesor del tejido duro y blando en los sitios de inserción de dispositivos de anclaje temporal, mediante el uso de TCHC en 10 pacientes, de los cuales evaluaron 10 regiones de hueso extra alveolar. La profundidad ósea media en la mayoría de las 10 regiones de interés extraalveolares fue de alrededor de $10 \mathrm{~mm}$, excepto la cresta infracigomática y la región media del paladar. La cresta infracigomática presentó la variación más grande de profundidad del tejido duro. 
Liu et al. $\left({ }^{29}\right)$ evaluaron el hueso alveolar bucal en la región de la cresta infracigomática con TCHC, para localizar zonas seguras de inserción de minitornillos cuando se debe distalizar la dentición en el maxilar superior. En la muestra de 60 pacientes consideraron 3 regiones. Sus resultados muestran que los porcentajes de la altura ósea del reborde de la cresta hacia el piso del seno fueron menores de $10 \mathrm{~mm}$ entre el segundo premolar y el primer molar (38\%), a nivel de la raíz mesovestibular del primer molar (52\%) y entre el primer y segundo molar (43\%). Concluyeron que la región ideal para la colocación de los minitornillos en el hueso alveolar bucal de la región de la cresta infracigomática para hacer la distalización de la dentición maxilar es entre primer y segundo molar.

El presente estudio es importante porque la cresta infracigomática es una zona para la colocación de minitornillos en ortodoncia, sin interferir en los movimientos deseados y permite conocer variaciones que pueden presentarse en las dimensiones de la cresta infracigomática en sentido bucal y verticalmente a nivel de la raíz mesiovestibular del segundo molar superior.

Gracias a una correcta medición de esta zona por parte del especialista en radiología oral, en las imágenes de TCHC, se pretende ayudar a que el ortodoncista se base en evidencias confiables para elegir la altura de inserción, el diámetro y longitud del minitornillo, que sea más apropiado y así el clínico puede evitar fracasos por pérdida de estabilidad, que generan incomodidad en el paciente, aumento del costo de tratamiento y dificultan la evolución del tratamiento.

El objetivo fue determinar la existencia de hueso infracigomático suficiente para la colocación de minitornillos, midiendo la altura y espesor óseo de la cresta infracigomática a nivel de la raíz mesiovestibular del segundo molar superior, a 2, 4 y 6 $\mathrm{mm}$, a partir de la cresta alveolar, utilizando TCHC. Adicionalmente, se compararon los promedios de las medidas de altura y espesor de la cresta infracigomática entre géneros.

\section{MATERIALES Y MÉTODOS}

Este estudio observacional, descriptivo, retrospectivo y transversal se realizó en pacientes entre 17 y 75 años que asistieron al Centro Radiológico Dento Análisis 3D, entre 2016 y enero de 2018 en Bogotá, remitidos para exámenes tomográficos. La muestra incluyó 127 volúmenes de $\mathrm{TCHC}$, tomadas entre el 1 de enero de 2016 y el 31 de enero de 2018, y que cumplían con los criterios de selección. La muestra fue calculada basándose en datos estadísticos de artículos publicados que midieron la misma zona $\left({ }^{3,29}\right)$.

Por tratarse de sujetos que asistieron al centro radiológico por razones ajenas al estudio, no hay vulneración ética alguna. En las tomografías computarizadas de haz cónico no se registraron nombres, apellidos ni otros datos que podrían llevar a identificar a alguno de los sujetos en mención.

Se incluyeron tomografías de pacientes con primer y segundo molar superior donde se observe la cresta infracigomática con imágenes tomadas en forma estandarizada y con registro completo de datos demográficos. Todas las imágenes de CBCT fueron tomadas en un escáner CS 9000 3D, a $90 \mathrm{kVp}$; $8 \mathrm{~mA}$, por 20 segundos y visualizadas a un voxel de 229 micras.

Se observó las imágenes mediante reconstrucción multiplanar en vistas axiales, coronales y sagitales, y se midió sobre cortes transaxiales. En el corte 
curvo, se posicionó el maxilar superior en la vista axial a nivel de la furca del segundo molar. La elaboración del arco se realizó de tal forma que el corte transaxial pase por la mitad de la raíz mesiovestibular del segundo molar (fig. 1). Así se obtiene la reconstrucción pseudopanorámica (fig. 2) y la vista de cortes transaxiales (fig. 3).

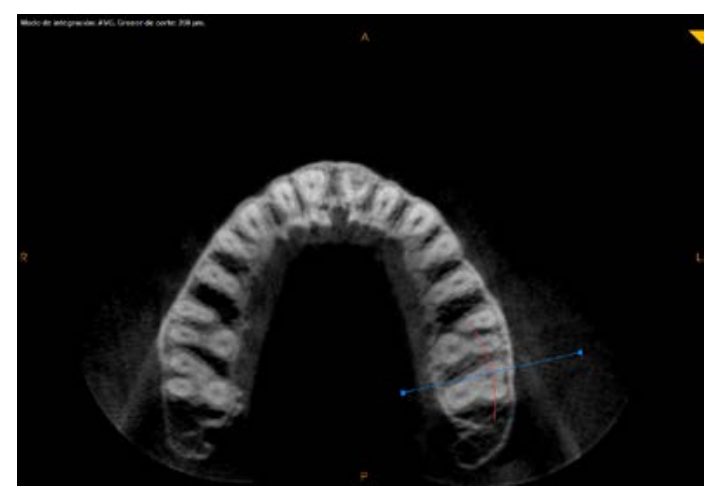

FIGURA 1. VISTA AXIAL PARA OBTENER IMAGEN PSEUDOPANORÁMICA

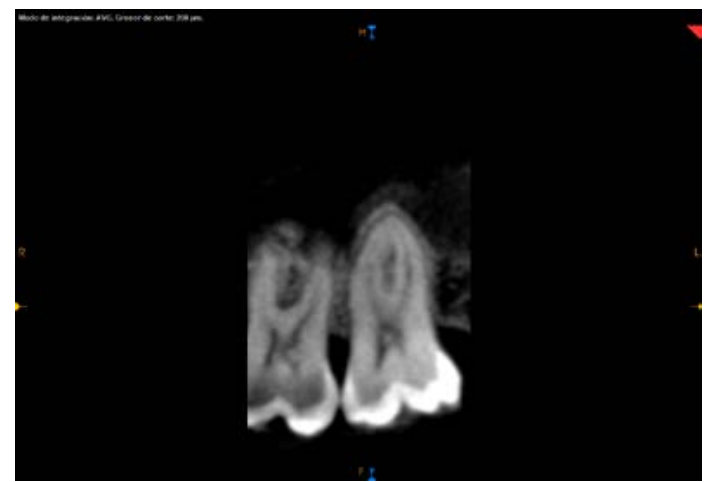

FIGURA 2. IMAGEN PSEUDOPANORÁMICA PARA OBTENER CORTES TRANSAXIALES

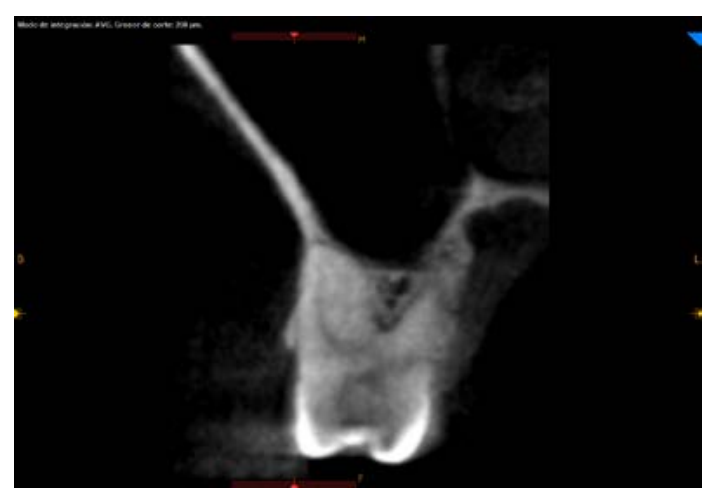

FIGURA 3. VISTA TRANSAXIAL CON RAÍZ MV DEL 7 EN CONTACTO CON LA CORTICAL VESTIBULAR
Se determinó si había o no hueso suficiente y ocurrió lo segundo cuando la lámina dura de la raíz mesiovestibular del 7 está en contacto con la cortical vestibular en cualquier tercio radicular (fig. 3) y cuando la altura sea menor a 10 $\mathrm{mm}$, la cual se toma como se describe en el punto número 5 (fig. 4).

En los casos en los cuales se determinó que sí existe hueso suficiente para la colocación de un minitornillo, se procedió a tomar las medidas definidas en la forma siguiente (fig. 5):

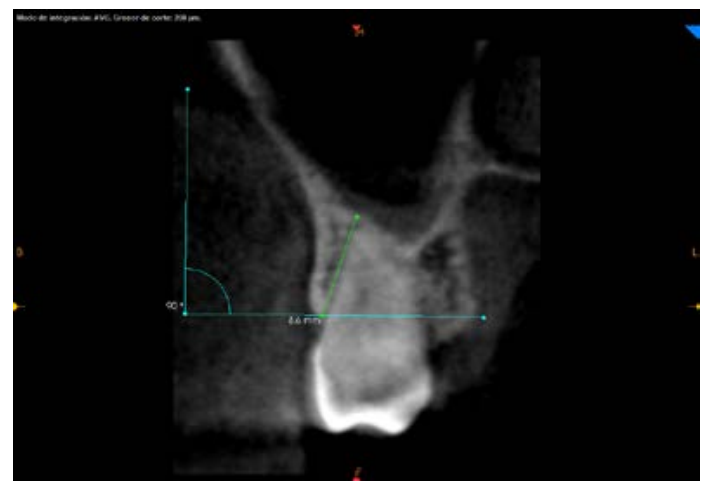

figura 4. Altura ósea suficiente

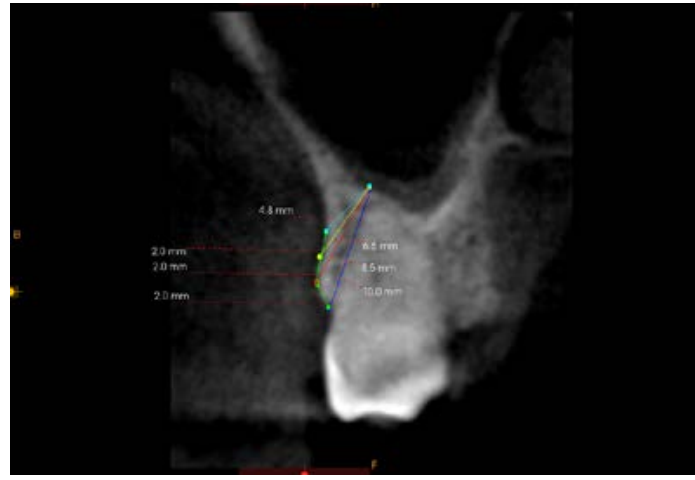

FIGURA 5. TOMA DE MEDICIONES

- Trazado de ángulo de $90^{\circ}$ cuyos lados pasen así: el vertical, paralelo al borde lateral de la ventana del corte transaxial y el horizontal tangente por la parte más inferior de la cresta alveolar.

- Se traza una línea que inicia desde la cresta alveolar y pase tangente a la superficie vestibular de la raíz 
mesiovestibular (MV-tang) hasta que corte con el piso del seno maxilar.

- Donde este plano MV-tang intercepta el piso del seno maxilar se ubica el punto $(\mathrm{ClZ})$.

- El punto donde intercepta este plano MV-tang con el plano horizontal tangente a la cresta se denomina punto X0.

- Se toma la altura vertical del hueso bucal midiendo la distancia entre los puntos $\mathrm{ClZ}$ y XO. Esta distancia se expresa como altura en $\mathrm{mm}$.

- A partir del punto XO hacia la porción cefálica y siguiendo el contorno de la cortical ósea vestibular, se miden $2 \mathrm{~mm}$ y se marca como el punto $\mathrm{X} 2$. Luego, se avanza $2 \mathrm{~mm}$ en sentido cefálico y se marca como punto $X 4 \mathrm{y}$ $2 \mathrm{~mm}$ más adelante se marca el punto $\mathrm{X} 6$. En todos los casos se sigue el contorno de la cortical vestibular.

- Se toman 3 medidas: 1) desde X2 hasta CIZ Ilamada distancia $2 \mathrm{~m}$; 2) desde $\mathrm{X} 4$ hasta $\mathrm{CIZ}$ Ilamada distancia $4 \mathrm{~m} ;$ y 3) desde X6 hasta CIZ llamada distancia $6 \mathrm{~m}$.

El mismo investigador repitió todas las mediciones después de una semana, de manera independiente, y se calculó así la confiabilidad intraoperador considerada excelente y el error aleatorio de las medidas es menor a 0,3 mm.

\section{RESULTADOS}

El total de la muestra corresponde a 127 imágenes tomográficas, de las cuales 77 $(60,6 \%)$ son de mujeres y $50(39,4 \%)$, de hombres. Los lados observados son 67 $(52,8 \%)$ del lado derecho y $60(47,2 \%)$ del lado izquierdo. El rango de edad está comprendido entre 17 y 75 años, con un promedio \pm D. E. de $42,3 \pm 13,1$.

La tabla 1 presenta los resultados de las observaciones cualitativas realizadas en 127 crestas infracigomáticas, a nivel del segundo molar superior. Solamente 70 $(55,1 \%)$ cumplían los criterios cualitativos para considerarlas como sitios con existencia de hueso.

La tabla 2 presenta los resultados de mediciones de la cresta infracigomática. De los 70 casos cualitativamente evaluados, solamente $28(40 \%)$ tenían una altura de la cresta infracigomática $>10 \mathrm{~mm}$. Las medidas en los 28 casos (intervalos de confianza del $95 \%$ en $\mathrm{mm}$ ) fueron las siguientes: espesor a $2 \mathrm{~mm}$ : 8,69-9,87 mm; a $4 \mathrm{~mm}: 7,71-8,89 \mathrm{~mm}$; a $6 \mathrm{~mm}: 6-7,17 \mathrm{~mm}$. La altura de la cresta ósea $(n=70)$ fue de $8,64-9,76 \mathrm{~mm}$.

Tabla1: Observaciones cualitativas en la muestra total

\begin{tabular}{|l|l|l|l|}
\hline Evaluación & No & Si & Total \\
\hline Presencia de hueso & $99(78,0 \%)$ & $28(22,0 \%)$ & 127 \\
\hline Contacto raíz-cortical & $70(55,1 \%)$ & $57(44,9 \%)$ & 127
\end{tabular}

TABLA 2: Resultados de MEDICIONES DE ALTURA Y ESPESOR DE HUESO EN CRESTA INFRACIGOMÁtICA DE SEGUNDO MOLAR SUPERIOR

\begin{tabular}{|l|l|l|l|l|}
\hline Medida & $\mathrm{n}$ & Promedio & D. E. & IC 95\% \\
\hline Altura ósea & 70 & $9,2 \mathrm{~mm}$ & $2,4 \mathrm{~mm}$ & $8,64-9,76$ \\
\hline Espesor a 2 mm & 28 & $9,28 \mathrm{~mm}$ & $1,6 \mathrm{~mm}$ & $8,69-9,87$ \\
\hline Espesor a 4 mm & 28 & $8,3 \mathrm{~mm}$ & $1,6 \mathrm{~mm}$ & $7,71-8,89$ \\
\hline Espesor a 6 mm & 28 & $6,6 \mathrm{~mm}$ & $1,55 \mathrm{~mm}$ & $6-7,17$ \\
\hline
\end{tabular}


Tabla 3: Comparación de las medidas entre géneros (Dimorfismo seXual Masculino/Femenino)

\begin{tabular}{|l|l|c|c|c|c|}
\hline Medida $(\mathrm{mm})$ & Sexo & $\mathrm{n}$ & Promedio $(\mathrm{mm})$ & Desv. Estándar $(\mathrm{mm})$ & $p$ \\
\hline Altura ósea & Hombres & 23 & 8,63 & 2,62 & 0,16 \\
\hline \multirow{2}{*}{ Espesor a 2 mm } & Mujeres & 47 & 9,48 & 2,3 & \\
& Hombres & 7 & 10,21 & 1,58 & 0,90 \\
\cline { 2 - 6 } Espesor a 4 mm & Mujeres & 21 & 10,02 & 1,65 & \\
& Hombres & 7 & 8,36 & 1,47 & 0,92 \\
\hline \multirow{2}{*}{ Espesor a 6 mm } & Mujeres & 21 & 8,29 & 1,64 & \\
& Hombres & 7 & 6,53 & 1,45 & 0,98 \\
\hline & Mujeres & 21 & 6,54 & 1,61 & \\
\hline
\end{tabular}

La tabla 3 muestra que no hubo diferencia significativa entre promedios de las medidas tomadas, al comparar los dos sexos $(p>0,05)$. Para la relación entre presencia o no de hueso y presencia o no de contacto raíz-cortical entre sexos, se encontró que no hay diferencia significativa entre hombres y mujeres ( $p$ > $0,05)$

\section{DISCUSIÓN}

La disponibilidad de hueso para colocar minitornillos con fines de anclaje ortodóncico en segundo molar superior parece ser, según los resultados de este estudio, bastante reducida. De 127 CBCT observadas, seleccionadas de una población de historias clínicas de un mismo centro radiológico, en Bogotá, Colombia, en 70 no había contacto raíz-cortical. En consecuencia, la muestra para toma de medidas se redujo a 70 imágenes para la medida de altura ósea. Como el espesor se midió solamente cuando esta altura era igual o mayor de $10 \mathrm{~mm}$, se redujo a 28 el número de medidas de espesor de la cresta infracigomática, que se tomó a 3 distancias: $2 \mathrm{~mm}, 4 \mathrm{~mm}$ y $6 \mathrm{~mm}$, a partir de la cresta alveolar.

El motivo por el cual hay más datos para la altura que para el espesor, es que la altura debía ser $>10 \mathrm{~mm}$ para considerarla adecuada para la colocación de minitornillos. El promedio de altura de la cresta infracigomática fue de $9,2 \mathrm{~mm}$ (intervalo de confianza del 95\% entre 8,6 y 9,8$)$. Sin embargo, no se puede considerar esta zona como segura para la colocación de minitornillos, porque solo en 28 casos fue $>10 \mathrm{~mm}$ y porque en muchos pacientes los datos de contacto raíz-cortical y evaluación cualitativa del hueso indicaban que no era un sitio adecuado. Los promedios de espesor de la cresta infracigomática van disminuyendo claramente a medida que aumenta la distancia, entre 2 y $6 \mathrm{~mm}$.

Se han usado diversos planos de referencia para las medidas de cortical y espesor óseo para la colocación de minitornillos, entre ellos el plano oclusal, el plano horizontal perpendicular al plano medio sagital, el plano de Frankfort y el plano palatino $\left({ }^{2,17,29,30,32}\right)$. En este estudio, se utilizó un plano tangente al reborde de la cresta alveolar debido a que se utilizaron tomografías de un sector donde no se podía usar el plano oclusal, que es el más utilizado.

Para comparar los resultados del presente estudio con los reportados en la literatura se debe tener en cuenta, ante todo, que en la mayoría de los estudios antecedentes la técnica de medición es diferente y ninguno estudia la zona vestibular de la cresta infracigomatica a nivel del segundo molar. 
Se encontraron estudios similares en cuanto a espesor de la zona infracigomática y la altura a nivel del primer molar. En el estudio de Liou et al. ( $\left.{ }^{3}\right)$, encontraron un espesor óseo de la cresta infracigomática sobre la raíz mesiovestibular del primer molar maxilar de 5,2 a 8,8 $\mathrm{mm}$, medido a una angulación de $40^{\circ}$ a $75^{\circ}$, respectivamente, con relación al plano oclusal; $y$ en el presente estudio se encontró una altura de la cresta infracigomática de 9,2 mm (intervalo de confianza del $95 \%$ entre 8,6 y 9,8 ), medido sobre la raíz mesiovestibular del segundo molar. Se indica que si se mide a mayor ángulo hay mayor espesor para la colocación de miniimplantes, lo cual coincide con los resultados del presente estudio, pero a nivel del segundo molar, aunque en este no se realizaron mediciones angulares.

Chen et al. $\left({ }^{28}\right)$ y Costa et al. $\left({ }^{25}\right)$ obtuvieron una profundidad ósea promedio de 5,89 $\mathrm{mm}\left({ }^{28}\right)$ y de $3,64 \mathrm{~mm}\left({ }^{25}\right)$. En el presente estudio, se encontró un promedio de 9,2 $\mathrm{mm}, 8,3 \mathrm{~mm}$ y $6,6 \mathrm{~mm}$ cuando se midió a 2, 4 y $6 \mathrm{~mm}$, respectivamente.

El estudio de Liu et al. $\left({ }^{29}\right)$ muestra que el hueso alveolar bucal es más grueso entre el primer y el segundo molar, y se va haciendo más grueso de la cresta alveolar hacia el piso del seno, lo cual no se puede corroborar con el presente estudio, ya que no se realizaron mediciones en igual sentido. Los porcentajes de la altura ósea del reborde de la cresta hacia el piso del seno fueron menores a $10 \mathrm{~mm}$ entre el segundo premolar y el primer molar (38\%), a nivel de la raíz mesovestibular del primer molar $(52 \%)$ y entre el primer y segundo molar (43\%). En el presente estudio, las mayores alturas fueron de 9,2 $\pm 2,4 \mathrm{~mm}$ a nivel de la raíz mesiovestibular del segundo molar.

En este estudio, no se realizaron mediciones en el corte axial de cortical a superficie radicular debido a que, según Laursen et al. $\left({ }^{33}\right)$, hay un cambio en la medición cuando se hace a un ángulo de $90^{\circ}$ a $45^{\circ}$ con relación al eje longitudinal del diente, lo que resulta en un incremento del espesor de la cortical ósea en un $45 \%$. Por lo tanto, se propone la medición del hueso en la dirección de la inserción del minitornillo. Sus resultados reportan que la distancia relativamente corta entre el seno maxilar y la cortical alveolar implica un riesgo de perforación del seno maxilar si el minitornillo es insertado con una inclinación en dirección apical. En consecuencia, se debe tener en cuenta que la inclinación aumenta el contacto de minitornillo con cortical, pero también hay mayor riesgo de perforación del piso del seno maxilar.

Otros estudios evalúan la cortical ósea a nivel de la cresta infracigomática. Entre ellos, Baumgaertel et al. $\left(^{5}\right)$ midieron el espesor de hueso cortical a 2, 4, y $6 \mathrm{~mm}$ de la cresta alveolar, pero en 30 cráneos secos y en el área interdental. Han reportado que el espesor de hueso cortical es mayor en mandíbula que en maxilar $\left({ }^{5,30}\right)$. En cuanto a diferencias entre la medida de espesor a diferentes distancias, Baumgaertel et al. $\left({ }^{26}\right)$ encontraron que era más delgado a $4 \mathrm{~mm}$; al igual que Ohiomoba et al. $\left({ }^{15}\right)$, quienes concluyen que el espesor cortical disminuye desde coronal hacia apical. Por otra parte, no han reportado diferencias entre lados ni diferencias relacionadas con la edad, en pacientes que han terminado el crecimiento. Chen et al. $\left({ }^{18}\right)$, al medir la cortical de la cresta infracigomática a nivel del primer molar a $7 \mathrm{~mm}$ sobre la cresta alveolar reportaron una medida de 2,6 $\mathrm{mm}$ de cortical. Teniendo en cuenta estas mediciones de la cortical ósea de la zona medida en este estudio y las medidas del espesor de la cresta infracigomática se puede sugerir la colocación de mini tornillos de 6 a $8 \mathrm{~mm}$ de longitud $\left({ }^{18,30,33}\right)$.

Las diferencias entre géneros han sido reportadas en muy pocos estudios. Chen et al. ${ }^{28}$ ) no encontraron diferencias 
significativas para la medición del espesor de la cortical de la cresta infracigomática, mientras que Lee et al. $\left({ }^{20}\right)$ encontraron diferencia significativa del espesor óseo, y es más grueso en hombres que en mujeres. En el presente caso, sí se exploraron estas diferencias, aunque para algunos casos el tamaño de muestra no era suficientemente representativo. Sin embargo, es bastante evidente que no parece haber diferencias estadísticamente significativas tanto para los aspectos cualitativos (Chi cuadrado del orden de 0,75 , $p$ muy superior a 0,05$)$ como para las dimensiones $(t$ de Student, $p>0,05)$.

En cuanto a las diferencias entre lados, en el presente estudio no se hizo una comparación porque esta variable se consideró irrelevante, teniendo en cuenta que los estudios ya citados $\left({ }^{18,20,26}\right)$ no encuentran diferencia y considerando que el lado se escogió por conveniencia en las tomografías, por ser el más visible y de mejor calidad.

\section{CONCLUSIONES}

1. En solo un cuarto de la población existe hueso para la colocación de minitornillos en esta zona.
2. De los casos que tienen hueso de cresta infracigomática, tanto las mediciones de altura como las medidas del espesor en $\mathrm{mm}$, indican que la región de la cresta infracigomática a nivel de la raíz mesiovestibular del segundo molar no es un sitio seguro para la colocación de dispositivos de anclaje temporal.

3. Al comparar las mediciones a 2, 4 y $6 \mathrm{~mm}$, solo se podría colocar minitornillos a $2 \mathrm{~mm}$ de distancia desde la cresta alveolar con una longitud máxima de $8 \mathrm{~mm}$.

4. No hay diferencia significativa entre hombres y mujeres en las medidas de altura y espesor.

Contribución del autor: Ana María Agudelo Agudelo Botero ha participado en la concepción del artículo, la recolección de información, su redacción y la aprobación de la versión final.

Fuente de financiamiento: Autofinanciado

Conflicto de interés: Ninguno 


\section{REFERENCIAS BIBLIOGRÁFICAS}

1. Reynders R, Ronchi L, Bipat S. Mini-implants in orthodontics: A systematic review of the literature. Am J Orthod Dentofacial Orthop 2009; 135: 564.e1-564.e19.

2. Holmes PB, Wolf BJ, Zhou J. A CBCT atlas of buccal cortical bone thickness in interradicular spaces. Angle Orthod 2015; 85: 911-9.

3. Liou E, Chen PH, Wang YC, Lin JC. A computed tomographic image study on the thickness of the infrazygomatic crest of the maxilla and its clinical implications for miniscrew insertion. Am J Orthod Dentofacial Orthop. 2007; 131: 352-6.

4. AISamak S, Gkantidis N, Bitsanis E, Christou P.Assessment of potential orthodontic mini-implant insertion sites base on anatomical hard tissue parameters: A systematic review. Int J Oral Maxillofac Implants 2012; 27: 875-87.

5. Gómez de Ferraris ME, Campos A. Histología y embriología bucodental. 2. ${ }^{\text {a }}$ edición. Madrid: Editorial Médica Panamericana; 2003.

6. Baxter D, Shroff M. Developmental maxillofacial anomalies. Semin Ultrasound CT MRI 2011; 32: 555-68.

7. Lindhe J. Periodontología clínica e implantología odontológica. 3. ${ }^{a}$ edición. Madrid: Editorial Médica Panamericana; 2001.

8. Norton N. Netter. Anatomía de cabeza y cuello para odontólogos. 2. a edición. Barcelona: Elsevier Masson; 2012.

9. Inaba $\mathrm{M}$ Evaluation of primary stability of inclined orthodontic mini-implants. J Oral Sci 2009; 51 (3): 347-53.

10. Eroglu T, Kaya B, Cetinsabin A, Arman A, Uckan S. Success of zigomatic platescrew anchorage system. J Oral Maxilofac Surg. 2010; (68): 602-05.

11. Farnsworth D, Rossouw PE, Ceen RF, Buschang PH. Cortical bone thickness at common miniscrew implant placement sites. Am J Orthod Dentofacial Orthop 2011; 139: 495-503.

12. Tseng YC, Hsieh $\mathrm{CH}$, Chen $\mathrm{CH}$, Shen YS, Huang IY, Chen $\mathrm{CM}$. The application of mini-implants for orthodontic anchorage. Int J Oral Maxillofac Surg 2016; 35: 704-7.

13. Echarri P, Favero L. Ortodoncia y microimplantes SARDAC technique. 2. ${ }^{\mathrm{a}}$ ed. Madrid: Ripano; 2012.

14. Fehrenbach M, Herring S. Anatomía ilustrada de cabeza y cuello. 1. ${ }^{a}$ ed. Ciudad de México: McGraw-Hill; 1996.

15. Ohiomoba H, Sonis A, Yansane A, Friedland B. Quantitative evaluation of maxillary alveolar cortical bone thickness and density using computed tomography imaging. Am J Orthod Dentofacial Orthop. 2017; 151 (1): 82-91.

16. Yao CC, Chang HH, Chang J, Lai HH, Lu SH, Chen YJ. Revisiting the stability of mini-implants used for orthodontic anchorage. J Formos Med Assoc 2015; 114: 1122-8. 
17. Fayed MM, Pazera P, Katsaros C. Optimal sites for orthodontic mini-implant placement assessed by cone beam computed tomography. Angle Orthod. 2010; 80: 939-51.

18. Chen $\mathrm{CH}$, Nakano $\mathrm{H}$, Liou E, Maki K. A cone beam computer tomographic study of the cortical bone thickness in different class II facial patterns. Orthod Waves 2010; 69: 131-37.

19. Migliorati M, Benedicenti S, Signori A, Drago S, Barberis F, Tournier H, SilvestriniBiavati A. Miniscrew design and bone characteristics: An experimental study of primary stability. Am J Orthod Dentofacial Orthop. 2012; 142: 228-34.

20. Lee HS, Choi HM, Choi DS, Jang I, Cha BK. Bone thickness of the infrazygomatic crest area in skeletal class III growing patients: A computed tomographic study. Imaging Sci Dent. 2013; 43: 261-6.

21. Sawada K, Nakahara K, Matsunaga S, Abe S, Ide Y. Evaluation of cortical bone thickness and root proximity at maxillary interradicular sites for mini-implant placement. Clin Oral Imp Res (Suppl. A100), 2013; 24: 1-7.

22. Ono A, Motoyoshi M, Shimizu N. Cortical bone thickness in the buccal posterior region for orthodontic mini-implants. Int J Oral Maxillofac Surg. 2008; 37: 334-40.

23. Wu J, Lu P, Lee K, Du J, Wang H, Chen C. Horizontal and vertical resistance strength of infrazygomatic mini-implants. Int J Oral Maxillofac Surg. 2011; 40: 521-5.

24. Hodges R, Atchison K, White S. Impact of cone-beam computed tomography on orthodontic diagnosis and treatment planning. Am J Orthod Dentofacial Orthop. 2013; 143: 665-74.

25. Costa A, Pasta G, Bergamaschi G. Intraoral hard and soft tissue depths for temporary anchorage devices. Semin Orthod. 2005; 11: 10-15.

26. Baumgaertel S, Hans M. Buccal cortical bone thickness for mini-implant placement. Am J Orthod Dentofacial Orthop. 2009; 136: 230-5.

27. Baumgaertel S, Hans M. Assessment of infrazygomatic bone depth for mini-screw insertion. Clin Oral Impl Res. 2009 (20): 638-42.

28. Chen YJ, Kao CT, Huang TH. Evaluation of ten extra-alveolar temporary anchorage device insertion sites by cone beam volumetric computer tomography: a pilot study. J Dent Sci. 2010; 5 (1): 21-9.

29. Liu H, Wu X, Yang L, Ding Y. Safe zones for miniscrew in maxillary dentition distalization assessed with cone-beam computed tomography. Am J Orthod Dentofacial Orthop. 2017; 151: 500-6.

30. Yang L, Li F, Cao M, Chen H, Wang X, Chen X et al. Quantitative evaluation of maxillary interradicular bone with cone-beam computed tomography for bicortical placement of orthodontic mini-implants. Am J Orthod Dentofacial Orthop. 2015; 147: 725-37. 
31. Prager T, Brochhagen HG, Mischkowski R, Jost-Brinkmann PG, Muller-Hartwich $\mathrm{R}$. Bone condition of the maxillary zygomatic process prior to orthodontic anchorage plate fixation. J Orofac Orthop. 2014; 76: 3-13.

32. Salah MM, Pazera P, Katsaros C. Optimal sites for orthodontic mini-implant placement assessed by cone beam computed tomography. Angle Orthodontist; 2010; 80 (5): 939-51.

33. Laursen M, Melsen B, Cattaneo P. An evaluation of insertion sites for mini-implants A micro-CT study of human autopsy material. Angle Orthod. 2013; 83 (2): 222-9. 